\title{
Robotization of Operations in the Petroleum Industry
}

\section{Hope Okoro*, Dagogo Godwin Orifama}

Department of Electrical and Electronic Engineering, University of Leeds, Leeds, United Kingdom

\section{Email address:}

hopeokoro@ymail.com (H. Okoro),dagoris2010@gmail.com (D. G. Orifama)

*Corresponding author

\section{To cite this article:}

Hope Okoro, Dagogo Godwin Orifama. Robotization of Operations in the Petroleum Industry. International Journal of Industrial and Manufacturing Systems Engineering. Vol. 4, No. 5, 2019, pp. 48-53. doi: 10.11648/j.ijimse.20190405.11

Received: September 28, 2019; Accepted: October 24, 2019; Published: October 31, 2019

\begin{abstract}
As the petroleum industry ventures into deep and ultra-deep waters in pursuit for increased oil production to meet the global energy demand, challenges of personnel health and safety and environmental pollution have gained a considerable amount of attention. One notable accident that has sparked this attention is the explosion of the Deepwater Horizon offshore petroleum platform that led to the spillage of oil into the water bodies. In tackling these challenges and preventing the reoccurrence of such accidents, the application of robotic automation in these environments, adjudged to be hostile and prone to high level of risk, provides the only option for safe and cost-effective operations. With the success of robotic automation in the manufacturing and aerospace industries, the oil and gas industry aim to take the advantages of increased reliability, accuracy and efficiency provided by robotics and automation technologies in improving operations and production both onshore and offshore and limiting the exposure of human workers to explosive and harsh onshore and offshore environments. In recent times, robotic technologies such as remotely operated vehicles (ROVs), autonomous underwater vehicles (AUVs), underwater welding robots and teleoperated unmanned production platforms have been deployed to facilitate smooth operation and production in ultra-deep waters. Thus, this paper investigates some of the various onshore and offshore operations such as exploration, tank and pipe inspection that require automation, the application of robotics and automation technologies to these operations, and the challenges and issues (such as human-robot interaction) involved in deploying robots in a dynamic environment.
\end{abstract}

Keywords: Robotics, Automation, Petroleum Industry Operations, Oil Spill, Pipe Inspection, Production Structure, Human-Robot Interaction

\section{Introduction}

In the wake of the current decline in oil and gas production and the projection for increased global energy demand as shown in figure 1 , the petroleum industry has begun to intensify its search for energy reserves in different locations. Some of these locations, the industry has ventured into, are challenging arctic regions, remote basins and deep $(400<\mathrm{d} \leq 1500 \mathrm{~m})$ or ultradeep $(\mathrm{d}>1500 \mathrm{~m})$ water [1-3]. These locations are described as hostile, dangerous and hard-to-reach and as such pose potential health and safety threats to personnel [1].

However, with the success recorded in the utilisation of robotics and automation in the manufacturing industry [6-8], the petroleum industry seeks to exploit advances in technology through robotics and automation to tackle these challenges.

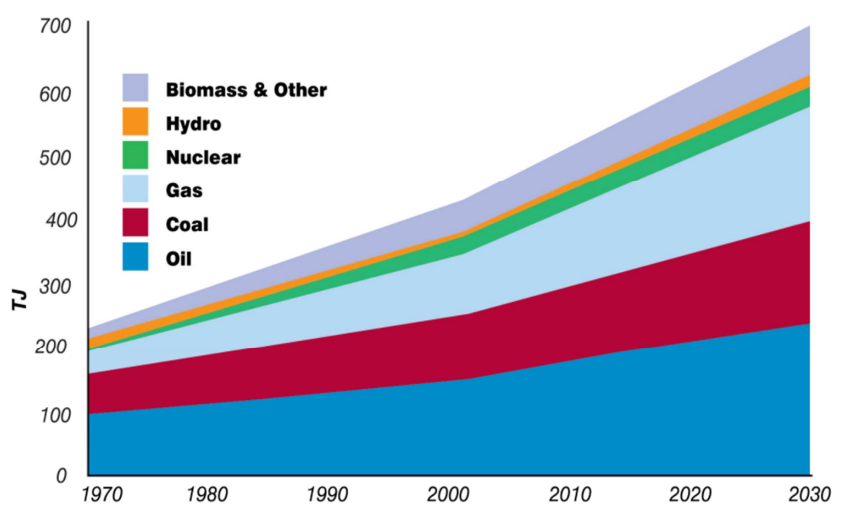

Figure 1. Projection of energy demand in the world [1, 4, 5].

Furthermore, environmental pollution resulting from oil and gas related activities such as oil spillage has placed a 
high demand on the deployment of robotics and automation to protect the environment. The oil spill in the US by the Deepwater Horizon offshore oil platform in 2010 [2] is one of such tragic events that released an estimated five million barrels of oil into the gulf in a period of 100 days [3]. Approximately US\$20 billion was spent by the British Petroleum (BP) in cleaning up the polluted area and paying compensation to affected individuals [4].

The transition to robotics and automation deployment is aimed at ensuring that both conventional and nonconventional oil and gas are obtained from new reserves, cost of operation is reduced, the risk to health and safety of personnel and the environment is minimised, and the manufacturing efficiency and quality are improved ultimately [5] Thus, this paper investigates the operations in the petroleum industry that demand the application of robotics and automation. It further describes the current technologies applied in these operations and concludes with the challenges and obstacles in the application of robotics and automation technologies in oil and gas industry.

\section{Industrial Processes in Oil and Gas}

The processes involved in ensuring the production and ultimate delivery of petroleum products in petroleum industry are divided into three categories: upstream, midstream and downstream. The upstream stage involves the search for crude oil in different locations, drilling up of exploratory oil wells, mounting appropriate production platforms and conveying these products to the middle stream. The midstream provides a link between supply and demand of petroleum products through processes such transportation, and storage of extracted crude oil in the upstream stage. The final stage is downstream. It involves the refinement of the crude oil to products such gasoline, diesel, etc., and the delivery to final consumers. From the described industrial processes, it is evident that many of these activities lend themselves to the application of robotics and automation. As such, some of these operations and the associated robotics and automation technologies are presented in the sections that follow.

\section{Exploration}

In oil exploration, the task of uncovering new oil reservoirs is carried out using seismic analysis by professionals such as reservoir engineers, geophysicists, and geologists. It is important for these professionals to determine not only the availability of crude oil but also its quantity and quality in a new reserve to justify the huge cost associated with setting up a production unit for petroleum extraction purposes [6]. Thus, information about the seabed and earth core are critical to providing hints of the presence hydrocarbon in the reserve.

Previously, human divers were used for this dangerous and capital-intensive operation [7]. Thus, currently, remotely operated vehicles (ROVs) and automated underwater vehicles (AUVs) equipped with advanced and suitable sensory devices are used in gathering data relevant to determining the potential presence of fossil fuel [14-15]. In the drilling of exploration crude oil where it is important to keep track of the outflow of gases and oil, ROVs are deployed to obtain real-time data that are sent to control centres for decision making by stationed personnel or automated systems [8]. This has led to the reduction of cost in the exploration of oil wells and improved health and safety of both human operators and the environment.

\section{Production Structure}

Production structures are erected for drilling purposes either to achieve a final confirmation of the presence of hydrocarbons in a new reservoir or to commence commercial production. These production structures could be either permanent or movable (floating) [9]. To ensure that multiple locations are explored with much lower costs for the presence of fossil fuels, movable platforms are mostly used. While for commercial drilling, permanent production structures are built. To support the extraction and drilling of oil and gas, various kinds of offshore structures shown in figure 2 are used. Manning these production platforms with human operators involves high operational cost and imposes health and environmental safety risks.

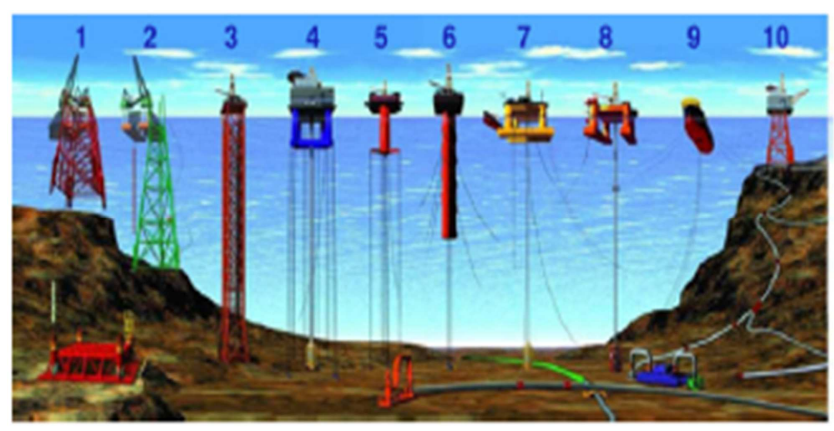

Figure 2. (1, 2) fixed platforms; (3) compliant tower; (4, 5) vertically moored tension leg and mini-tension leg platform; (6) spar; (7, 8) semisubmersibles; (9) Floating production, storage and offloading (FPSO) facility; (10) sub-sea completion and tie-back to host facility [9].

Thus, with the application of automation, remotely controlled unmanned platforms that are teleoperated using satellite communication can be deployed. With such platforms, skilled personnel can be positioned at a safe location to monitor closely all process on the offshore facilities. This ensures that production in the offshore environment is carried out for a long period of time (six months or even a year) with little or no safety risk to human operators [10]. One example of such a platform is the advanced remote-controlled unmanned platform developed by Statoil-Hydro and SINTEF [11]. This platform is equipped with sensors, audio, redundant manipulators, and visual feedback which are used by control centre operators located in safe location [11]. Thus, ensuring cost reduction and time-saving required for deploying skilled operators to these offshore platforms for monitoring and supervisory purposes. 


\section{Pipe Inspection}

One common operation that occurs in the petroleum industry is the transportation of petroleum products such as gas, oil and other fluids from areas where they are produced to areas where they are distributed. To achieve this, pipes (laid either underwater or underground) are utilized. In most cases, these pipes are exposed to unfavourable conditions of dust, hot, cold and humidity due to the nature of the environment. As such, these pipes often have associated issues of corrosion, cracks, shock loading, thermal cycling and joint failure that could lead to leakage of petroleum products [20-21]. Such leakage is undesirable because it results in both product and revenue loss, environmental pollution and safety issues [12]. Thus, a need for proper and frequent pipe inspection and maintenance for early detection of these flaws in the pipes to prevent revenue loss and hazard to the environment.

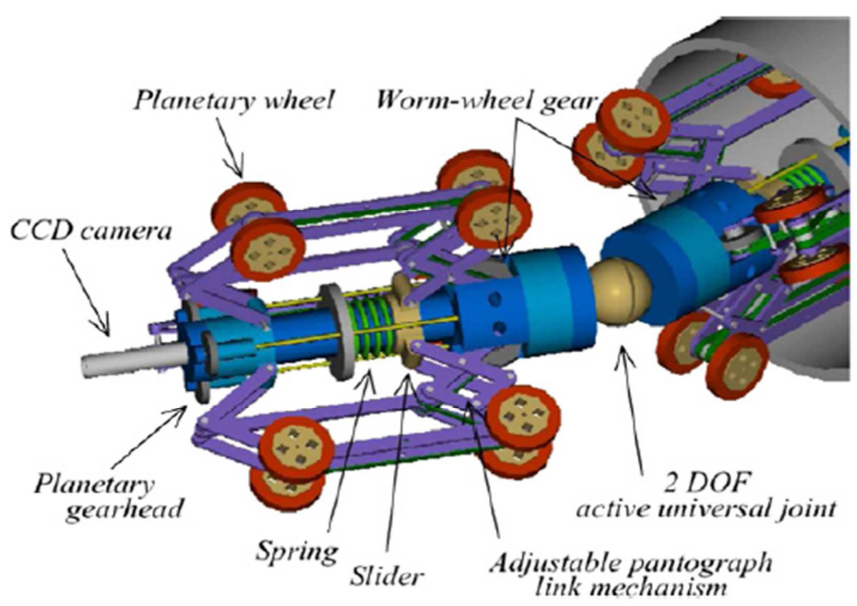

Figure 3. Wheel Robot for pipe inspection [13].

Traditionally, for underground pipes, the process of carrying out pipe inspection involves excavating the soil and detecting manually the position of the flaws in the pipes. This process is not only inconvenient but expensive. However, with the use of robots in pipe inspection (figure 3), all that is required is the insertion of the appropriate robot (depending on the flaw to be detected) at the inlet point of the pipe and the remote supervision of the robot as it travels through the pipe. Depending on the type of inspection to be carried out in the pipe, these robots are equipped with suitable inspection tools that use technologies such as acoustic, ultrasonic, cameras, and x-rays. The categorization of pipe inspection robots is based on parameters such robots shape and size, steering machinery, propelling mechanism, detection technology and control mechanism [4]. These parameters are designed to allow for the adaption of the robot to required purpose of inspection, structure and dimension of pipe [14].

\section{Tank Inspection}

Another frequently performed operation in the petroleum industry is the inspection of gigantic metallic storage tanks, located both onshore and offshore, for petroleum-based products. Corrosion due to compounds such as iron sulphide and hydrogen sulphide in crude petroleum products contained in tanks often make these tanks prone to leakage. Hence, the need for tank inspection to prevent leakages which pose a safety risk, lead to environmental pollution and loss of revenue [12]. Carrying out human tank inspection requires completely emptying the tank and stopping all the production for weeks [15]. This is done because of the presence of dangerous chemicals such as Hydrogen sulphide in these tanks. As such, human inspection of tanks is not only a lengthy process but expensive and hazardous from a safety perspective [16]. This has allowed for automated inspection using tank inspection robots (TIRs) even while these storage tanks are filled with petroleum products and with no halt in processes utilising the petroleum tank.

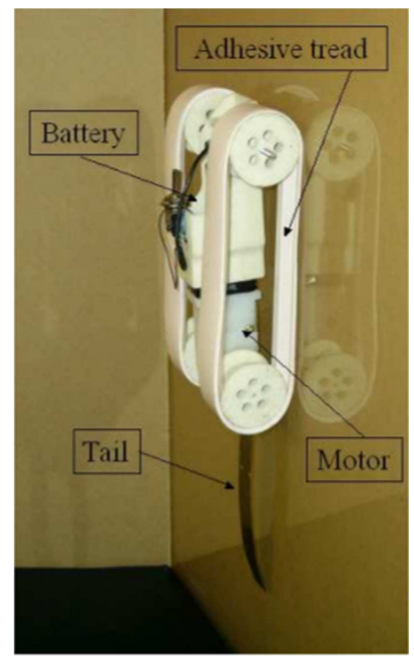

Figure 4. Wall climbing tank inspection robot [17].

The principle of climbing the tank under inspection is mainly used in the categorisation of TIRs [18]. As such, the adhesion machinery and the locomotion principle of tank climbing are utilized [19]. In adhesion mechanism [17], magnetism [20], vacuum suction [21], attachment mechanisms such as rails or pegs and grippers/clamps [22] are used to allow for climbing. On the other hand, wheels, tracks, legs and actuator-based devices are used in locomotion principle of climbing.

\section{Oil Spill Operations}

Spillage of oil can take place at any of the identified stages of petroleum production [23]. Spillage is occasioned by factors such as structural failure, accidents, operational and human error, natural disaster (earthquakes) and even vandalism or terrorism [24]. More recently, the prevention of spillage of oil both onshore and offshore has been one of the major challenges that have plagued the oil and gas industry. Offshore oil spill leads to severe damage to marine life because of its injection of harmful substances into the sea and this impacts negatively on the livelihood of people whose 
occupation is fishing and carrying out other marine activities. Also, huge revenue losses are recorded by companies in the event of oil spillage. For example, the oil spill in the US by the Deepwater Horizon offshore oil platform resulted in the release of over 5 million barrels of crude oil into the seawater which affected 180000 square kilometres of sea surface [3]. This led to the loss of billions of dollars in providing personnel, vessels, aircraft, and dispersant for the cleanup operation. To minimise the occurrence and severity of oil spill, the oil and gas industry has taken steps in utilizing advances in technology for potential detection of oil spill scenarios and improvement of results of oil spill clean-up operations.

Pipes and tanks inspection robots are currently being used to carry out an autonomous inspection of transportation and storage equipment. As such, leakages are detected even before they occur. Thus, ensuring the prevention of oil spillage due to pipes and tanks leakage which causes pollution to the environment. Furthermore, ROVs or AUVs equipped with cameras are deployed to capture and transmit visual images of the oil spill affected area for purposes of spill detection and clean-up. Other remote sensing technologies such video cameras, infrared sensors, ultraviolet sensors, microwave sensors and laser fluorosensors [25] are used to obtain information like the thickness of oil slick of the oil spill region. As such, companies and regulatory bodies are better informed about the severity of the spill and possible counter spill measures to be adopted.

The conduction of oil spill clean-up operations to curtail its spread to other unaffected regions is carried out after oil spillage detection and the location of affected region by relevant sensing methods. Traditionally, this was done using skimmers which are mechanical devices used for separating the spilled oil from the water surface [26] and in-situ burning which involves the burning of the spill region [27]. However, due to the inefficiency and the potential environmental pollution of these methods, robotic systems having an integrated structure for managing oil spillage have been developed for this purpose. These robotic systems are driven by swarm intelligence (SI) which provides the capacity to cooperate with multiple robots to form a tight cluster leading to faster and superior performance when compared to a single robot [28, 29]. These swarm robots are equipped with appropriate sensors for oil detection, skimmers for oil recovery, controllers for smart decision making, propulsion unit for drive enablement, and a power source for 24 hours continuous operation in one complete charge sequence [29].

\section{Challenge of Human-Robot Interaction}

In addition to the challenges of hostile geographical location, hardware and communication constraints [1] identified with the use of robots in the petroleum industry is the issue of human-robot interaction. As robots find application in tele-inspection (which allows for remote inspection) and teleoperation (for maintenance and repairs), it has brought to the fore the issue of trust and accountability in the use of robots. It has also thrown up questions about where responsibility lies in the use of robots for carrying out safe and correct industrial tasks, and the relationship between robots and field operators whose tasks are been performed by robots. According to [30], field operators are more likely to perceive non-humanoid forms of robots as friendlier than humanoid robots and [31] identified that greater responsibility is taken by field operator in ensuring that tasks are completed when working with non-humanoid robots. Also, too little autonomy of robots is envisaged to result in waste of time and resources as human operators lose sight of their responsibility while attending to the robots. On the other hand, the awareness of human operators to the current situation in the oil field is reduced if robots are completely autonomous. Thus, critical to ensuring better performance in the use of robotics in the petroleum industry is the need for the careful consideration of the interaction between human operators and robots.

\section{Conclusion}

The robotization of operations in the oil and gas industry has been identified in this paper to bring about accuracy and efficiency of operations, cost reduction and improved safety to operators and the environment. This paper further described some application areas such as oil exploration, oil spillage management, tank and pipe inspection for robotics and automation utilisation. Furthermore, the relevant robotic and automation technologies applied in these operations were succinctly captured and described. However, human-robot interaction presents a major challenge in the use of robots in the petroleum industry. Thus, because of hazards and unpredictability associated with onshore and offshore environments, the use of semi-autonomous robots is still an excellent choice, at least for the near future technology.

\section{References}

[1] S. Stanvinoha, H. Chen, B. Zhang and T. Fuhlbrigge, "Challenges of robotics and automation in offshore oil and gas industry," The 4th Annual IEEE International Conference on Cyber Technology in Automation, Control and Intelligent Systems, pp. 557-562, 2014.

[2] A. A. David, E. Persson and C. Heyer, "Real-world demonstration of sensor-based robotic automation in oil and gas facilities," 2011 IEEE/RSJ International Conference on Intelligent Robots and Systems, pp. 235-240, September, 2011.

[3] T. McGee, "Geologic characteristics in the vicinity of the Deepwater Horizon oil spill," 2010 IEEE/OES Baltic International Symposium (BALTIC), pp. 1-5, 2010.

[4] A. Shukla and H. Karki, "A review of robotics in onshore oilgas industry," 2013 IEEE International Conference on Mechatronics and Automation, pp. 1155-1160, 2013. 
[5] H. Roman, B. A. Pellegrino and W. R. Sigrist, "Pipe crawling inspection robots: an overview," IEEE Transaction on Energy Conversion, vol. 8, no. 3, pp. 576-583, 1993.

[6] W. Leffler, R. Pattarozzi and G. Sterling, Deepwater Petroleum Exploration and Production: A nontechnical Guide, second ed., Oklahoma, USA: PennWell Books, 2011.

[7] B. Solvang, Z. Deng and T. Lien, "A methodological framework for developing ROV-manipulator systems for underwater unmanned intervention," Oceans 2001. MTS/IEEE Conference and Exhibition, vol. 2, pp. 1085-1091, 2001.

[8] I. Tomoye, S. Hiroyoshi, I. Junya, M. Obiki and T. Kazuhiro, "Small-size ROV launched from underwater TV system for observation in scientific drillings," 2015 IEEE OCEANS, Genova, pp. 1-5, 2015.

[9] A. Shukla and H. Karki, "Application of robotics in offshore oil and gas industry-A review Part 2," Robotics and Autonomous Systems, vol. 75, pp. 508-524, 2016.

[10] O. Alyafei, "Well services operations in offshore unmanned platform: challenges and solutions," International Petroleum Technology Conference, pp. 1-6, 2014.

[11] A. Pinosofa, A. Ramirez, Y. Ravelo and O. Cruz, "Unmanned offshore platforms: Automation kit," Society of Petroleum Engineers, pp. 1-6, 2010.

[12] H. Peter, A. Hatem, R. Peter and B. Brett, "Monocular visual odometry for robot localization in LNG pipes," 2011 IEEE International Conference on Robotics and Automation, pp. 3111-3116, 2011

[13] A. Shukla and H. Karki, "Application of robotics in onshore oil and gas industry-A review Part 1," Robotics and Autonomous Systems, vol. 75, pp. 490-507, 2016.

[14] D. Edwin and S. Stefano, "Basic maneuvers for an inspection robot for small diameter gas distribution mains," 2011 IEEE International Conference on Robotics and Automation, pp. 3447-3448, 2011 .

[15] A. S. Abdulla, A. M. Khalil, A. A. Mohamed, H. Karki and S. Fok, "Localization of a submersible mobile inspection platform in an oil storage tank," 7th IEEE International Symposium on Mechatronics and its Applications, pp. 1-6, 2010 .

[16] B. Zhiqiang, G. Yisheng, C. Shizhong, Z. Haifei and Z. Hong, "A miniature Biped Wall-Climbing Robot for Inspection of Magnetic Metal Surfaces," 2012 IEEE International Conference on Robotics and Biomimetics, pp. 324-329, 2012.

[17] C. Menon, M. Murphy and M. Sitti, "Gecko Inspired Surface Climbing Robots," 2004 IEEE International Conference on Robotics and Biomimetics, pp. 431-436, 20014.

[18] Y. Wang, S. Liu, D. Xu, Y. Zhao, H. Shao and X. Gao, "Development and application of wall-climbing robots," 1999 IEEE International Conference on Robotics and Automation, vol. 2, pp. 1207-1212, 1999.

[19] D. Weiguang, W. Hongguang, L. Zhenhui, J. Yong and X. Jizhong, "Development of a wall-climbing robot with bipedwheel hybrid locomotion," 2013 IEEE/RSJ International Conference on Intelligent Robots and Systems, pp. 2333-2338, 2013.
[20] A. Oliveira, M. Silva and R. Barbosa, "Architecture of a wheeled climbing robot with dynamic adjustment of the adhesion system," IEEE 8th International Symposium on intelligent Systems and Informatics, pp. 127-132, 2010.

[21] M. Akhtaruzzaman, N. I. Samsuddin, N. Umar and M. Rahman, "Design and development of a wall climbing robot and its control system," 2009 12th International Conference on Computers and Information Technology, pp. 309-313, 2009.

[22] R. Aracil, R. Saltaren and O. Reinoso, "A climbing parallel robot: a robot to climb along tubular and metallic structures," IEEE Robotics and Automation Magazine, vol. 13, no. 1, pp. 16-22, 2006.

[23] F. Merv, The Basics of Oil Spill Cleanup, CRC Press, 2012.

[24] M. Fingas, Oil Spill Science and Technology: Prevention, Response and Cleanup, Burlington, USA: Elsevier Inc., 2011.

[25] P. Eriksen, "Leakage and oil spill detection utilising active acoustic system," 2013 IEEE International Underwater Technology Symposium (UT), pp. 1-8, 2013.

[26] F. Isamu and Y. Muneo, "An Onboard Air Conveyer Oil Skimmer," OCEANS, pp. 1-6, 2015.

[27] N. Barnea, "Use of in-situ burning as part of the oil spill response toolbox," MTS/IEEE OCEANS, vol. 3, pp. 1457$1462,1999$.

[28] M. Pashna, R. Yusof and S. Yazdani, "Analysis of prediction methods for swarm robotic - in the case of oil spill tracking," 2015 IEEE Asian Control Conference, pp. 1-5, 2015.

[29] N. Kakalis and Y. Ventikos, "Robotic swarm concept for efficient oil spill confrontation," Elsevier Journal of Hazardous Materials, vol. 154, pp. 880-887, 2008.

[30] V. T. L. Groom, P. Ochi and C. Nass, "I Am My Robot: The Impact of Robot-building and Robot Form on Operators," 2009 4th ACM/IEEE International Conference on HumanRobot Interaction (HRI), pp. 11-16, 2009.

[31] P. Hinds, T. Roberts and H. Jones, "Whose job is it anyway? a study of human-robot interaction in a collaborative task," Human Computer Interaction, vol. 19, no. 1, pp. 151-181, 2004.

[32] S. Stanvinoha, H. Chen, B. Zhang and T. Fuhlbrigge, "Exploring robotic applications in offshore oil and gas industry," The 4th Annual IEEE International Conference on Cyber Technology in Automation, Control and Intelligent Systems, pp. 557-562, 2014.

[33] World Nuclear Association, "Uranium, Electricity and Climate Change," December 2012. [Online]. Available: http://www.world-nuclear.org/information-library/energy-andthe-environment/uranium,-electricity-and-climatechange.aspx. [Accessed 25 April 2018].

[34] M. W. Thomas, R. S. Sutton and P. J. Werbos, "Applications of Neural Networks in Robotics and Automation for Manufacturing," IEEE Journal, pp. 365-385, 1995.

[35] H. Chen, W. Eakins, J. Wang, G. Zhang and T. Fuhlbrigge, "Robotic wheel loading process in automotive manufacturing automation," in 2009 IEEE/RSJ International Conference on Intelligent Robots and Systems, St. Louis, USA, 2009. 
[36] H. Clint, "Human-robot interaction and future industrial robotics applications," 2010 IEEE/RJS International Conference on Intelligent Robots and Systems, pp. 4749-4754, 2010.

[37] T. Wu, S. Lu and Y. Tang, "An in-pipe internal defects inspection system based on the active stereo omnidirectional vision sensor," 2015 12th International Conference on Fuzzy Systems and Knowledge Discovery (FSKD), pp. 2637-2641, 2015.

[38] I. Megumi, N. Taro and M. Dai, "Development of an in-pipe inspection robot for narrow pipes and elbows using pneumatic artificial muscles," 2012 IEEE/RSJ International Conference on Intelligent Robots and Systems, pp. 926-931, 2012.

[39] M. Mehran, H. Najjaran, R. Paranjape and S. Poozesh, "Dynamic analysis and control of a robotic pipe crawler," 2008 IEEE/RSJ International Conference on Intelligent Robots and Systems, pp. 4182-4182, 2008.

[40] H. Schempf, B. Chemel and N. Everett, "Neptune: above- ground storage tank inspection robot system," IEEE Robotics and Automation Magazine, vol. 2, no. 2, pp. 9-15, 1995.

[41] F. Carvalho, A. Raposo, I. Santos and M. Galassi, "Virtual reality techniques for planning the offshore robotizing," 2014 12th IEEE Conference on Industrial Informatics, pp. 353-358, 2014.

[42] L. Martin, S. Fredrik, K. Aasly, E. Steinar, M. Zylstra and M. Pardey, "ROV based drilling for deep sea mining exploration," Oceans 2017, Aberdeen, pp. 1-6, 2017.

[43] K. Clayton, M. Chris, C. Richard, S. Hanumant, B. John, E. Ryan, J. Michael, N. Ko-ichi, R. Chris, S. Taichi, S. A. Robert and W. Claire, "Deep sea underwater robotic exploration in the ice-covered Arctic ocean with AUVs," 2008 IEEE/RSJ International Conference on Intelligent Robots and Systems, pp. 3654-3660, 2008.

[44] C. J. Maria, P. Goncalves, A. Martins and E. Silva, "Visionbased assisted teleoperation for inspection tasks with a small ROV," 2012 IEEE Oceans, pp. 1-8, 2012. 